\title{
Special issue: Engineering of Computer-Based Systems
}

\author{
Roy Sterritt
}

Received: 31 May 2013 / Accepted: 30 June 2013 / Published online: 28 July 2013

(C) Springer-Verlag London 2013

The Engineering of Computer-Based Systems (ECBS) Community is in its 21 st year and is concerned with formulating and advancing methods, techniques and tools for engineering CBS'. The community's long-termheld belief was that Computer-Based Systems Engineering (CBSE) is a different discipline, that is, to effectively engineer today's and tomorrow's complex systems requires a multidisciplinary role with both the skillsets of a Systems Engineer and a Software Engineer and an joint evolution of both.

This long-term held belief that CBSE is a different discipline which has been vindicated by the recent main stream adoption of the Cyber-Physical Systems (CPS) as a field (Fig. 1). We see the terms CBS and CPS as interchangeable, with CPS reflecting a more modern term and CBSE the original discipline. Both CBS and CPS are effectively seeking to establish Innovations in Systems and Software Engineering. This special issue represents a selection of extended work from the last few years of ECBS technical meetings.

\section{Roy Sterritt}

Associate Editor

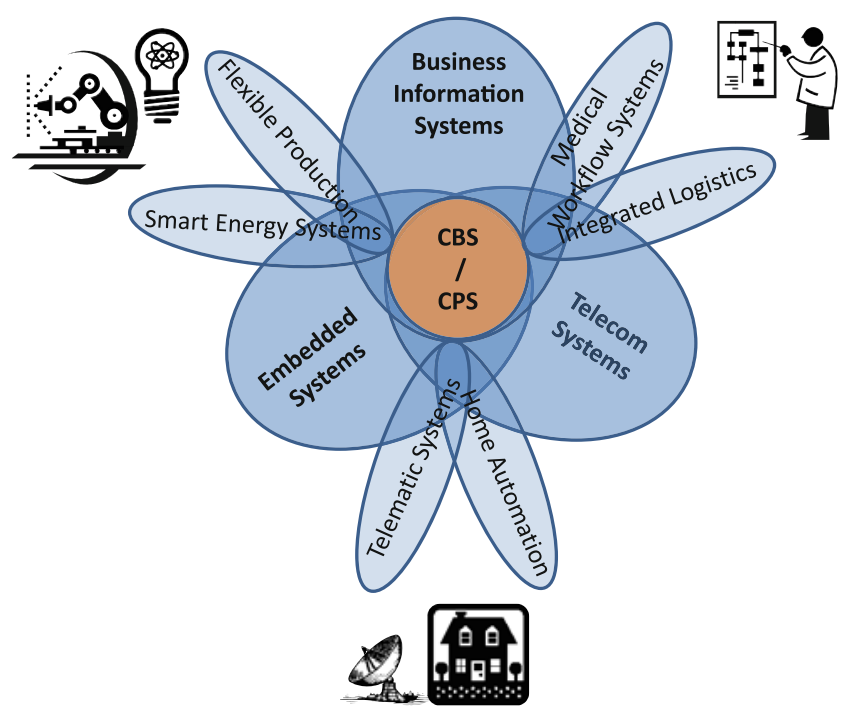

Fig. 1 Computer-based systems and cyber-physical systems. Figure courtesy of Bernhard Schätz, extracted from 2012 ECBS PC Chair report in TCECBS Newsletter, April 2012, http://tab.computer.org/ ecbs/newsletter/2012-04-tc-ecbs-news.pdf

R. Sterritt $(\varangle)$

Jordanstown, Northern Ireland

e-mail: r.sterritt@ulster.ac.uk 